\title{
Status of alkenone paleothermometer calibration: Report from Working Group 3
}

\section{F. Prahl}

College of Oceanic and Atmospheric Sciences, Oregon State University, Oceanography Administration Building 104, Corvallis, Oregon 97331-5503 (fprahl@oce.orst.edu)

\section{T. Herbert}

Department of Geological Science, Brown University, Box 1846, Providence, Rhode Island 02912 (timothy_herbert@brown.edu)

\section{S. C. Brassell}

Biogeochemical Laboratories, 1005 East 10th Street, Indiana University, Bloomington, Indiana 47401

(simon@indiana.edu)

\section{N. Ohkouchi}

Clark Laboratory, Woods Hole Oceanographic Institution, MS-23, 360 Woods Hole Road, Woods Hole, Massachusetts 02543 (nohkouchi@whoi.edu)

\section{Pagani}

Earth Sciences Department, University of California, Santa Cruz, Earth and Marine Sciences Building, Santa Cruz, California 95064 (pagani@es.ucsc.edu)

\section{Repeta}

Fye Laboratory, Woods Hole Oceanographic Institution, MS-4, 360 Woods Hole Road, Woods Hole, Massachusetts 02543 (drepeta@whoi.edu)

\section{A. Rosell-Melé}

Department of Geography, University of Durham, South Road, Durham DH1 3LE, England, UK (antoni.rosell@durham.ac.uk)

\section{E. Sikes}

SEMS/Geology, University of Auckland, Private Bag 92019, Auckland, New Zealand (esikes@auckland.edu)

[1] Abstract: The alkenone unsaturation index, $\mathrm{U}_{37}^{\mathrm{K}^{\prime}}$, has now proven its worth as a tool for paleothermometry. $\mathrm{U}_{37}^{\mathrm{K}^{\prime}}$ measured in most modern sediments throughout the World Ocean can be translated using established calibrations into realistic, seemingly reliable estimates of mean annual temperature at the sea surface (SST). However, it remains mysterious why water temperature estimates based on this biotic index correspond to "mean annual" SST and whether such estimates apply back in geological time. Solving these mysteries is imperative and will require thoughtful, concerted research effort by the biological, chemical, and geological oceanographic community. This report summarizes what is now known about alkenones, in particular, their use in estimating the growth temperature of specific haptophyte algae that synthesize and export these compounds to the marine sediment record. It highlights future field and laboratory research directions that should be taken to clarify and bolster utility of alkenones as a generally valued paleoceanographic tool. 
Keywords: Haptophytes; alkenones; euphotic zone; paleothermometer; diagenesis; sediment record.

Index terms: Organic marine chemistry; plankton; biogeochemical processes; paleoceanography.

Received February 22, 2000; Revised October 11, 2000; Accepted October 11, 2000;

Published November 7, 2000.

Prahl, F., T. D. Herbert, S. Brassell, N. Ohkouchi, M. Pagani, A. Rosell-Melé, D. Repeta, and E. Sikes, 2000. Status of alkenone paleothermometer calibration: Report from Working Group 3, Geochem. Geophys. Geosyst., vol. 1, Paper number 2000GC000058 [4880 words, 7 figures]. Published November 7, 2000.

Theme: Alkenones

Guest Editor: John Hayes

\section{Introduction}

\subsection{Initial Vision}

[2] In the mid-1980s a provocative article was published by Brassell et al. [1986] suggesting that the marine fossil record for long-chain alkenones, biomarkers synthesized by a restricted subset of haptophyte algae, provides valuable insight to climate-forced changes in sea surface temperature (SST). The timescale of change discussed in that article was glacial/interglacial. However, clearly, potential exists to evaluate changes on 100-year timescales [Eglinton et al., 1992] and perhaps as short as interannual, e.g., El Niño [Kennedy and Brassell, 1992]. Temporal resolution of paleoceanographic reconstruction is ultimately only limited by the stratigraphic quality of a given sediment core record, which in turn, is governed by a combination of factors, including sediment accumulation rate, lateral redistribution events, postdepositional mixing processes, etc.

[3] The initial vision of Brassell et al. [1986] led to a flurry of international research into the biogeochemistry of alkenones. The overall outcome of this collective effort has revealed that alkenone unsaturation patterns provide an unprecedented, robust tool for paleoceano- graphic assessment of changes in water temperature at the sea surface.

\subsection{Summary of Key Findings From Mid-1980s to the Present}

[4] $1 . \mathrm{U}_{37}^{\mathrm{K}^{\prime}}$ values display a systematic latitudinal variation in surface sediments throughout the world ocean [Brassell, 1993].

[5] 2. The relative abundance of long-chain alkenones with two and three double bonds are without question temperature dependent (Figure 1). All findings from laboratory culture work with alkenone-producing haptophytes done to date endorse this statement [Conte et $a l ., 1998 \mathrm{a}$, and references therein].

[6] 3. The first culture experiment with a strain of Ehux isolated from the subarctic Pacific showed that alkenone unsaturation, gauged by the index $\mathrm{U}_{37}^{\mathrm{K}^{\prime}}(\equiv[37: 2] /([37: 2]+[37: 3]))$, varies in a linear fashion $\left(r^{2}=0.994, n=22\right)$ over the range of growth temperatures $T$ from $8^{\circ}$ to $25^{\circ} \mathrm{C}\left(\mathrm{U}_{37}^{\mathrm{K}^{\prime}}=0.034 T+0.039\right.$ [Prahl et al., 1988]). The first field test of this laboratory calibration showed that the average alkenoneproducing haptophyte growing in ocean surface waters conforms quite remarkably, albeit not perfectly, to this relationship [Prahl and Wakeham, 1987]. 


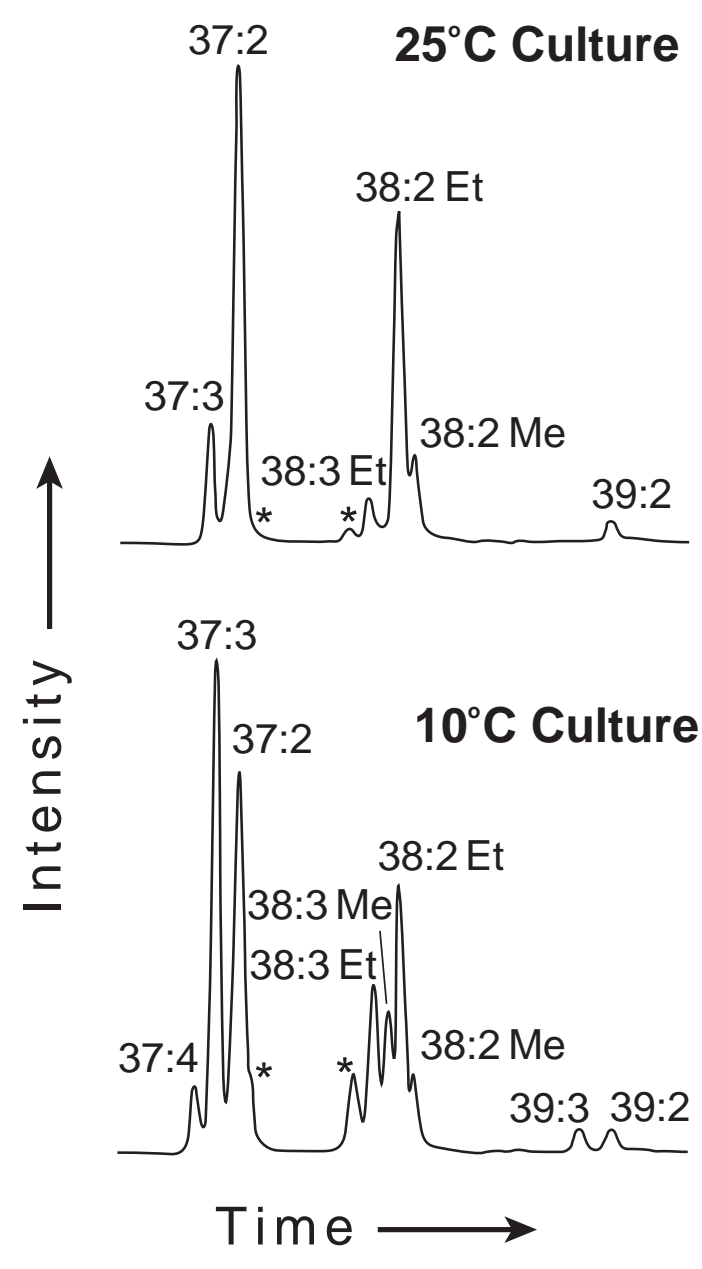

Figure 1. Partial gas chromatograms of the alkenone/alkenoate signature biosynthesized by Emiliania huxleyi (strain 55a) grown isothermally in batch culture at two different temperatures. Reprinted from Prahl et al. [1988], with permission of Elsevier Sceince.

[7] 4. Various lines of investigation have shown values of $\mathrm{U}_{37}^{\mathrm{K}^{\prime}}$, once set biochemically by the algae, are not significantly altered by degradation in sedimentary processes [e.g., Conte et al., 1992; Freeman and Wakeham, 1992; Madureira et al., 1995; Prahl et al., 1989, 1993; Teece et al., 1998]. What rains down to and becomes incorporated in the seabed reflects in some direct way the integrated seasonal temperature record for growth of alkenone producers in surface waters.

[8] 5. Consistent with this conclusion, core top measurements made on sediments collected between $60^{\circ} \mathrm{N}$ and $60^{\circ} \mathrm{S}$ in the world oceans show a remarkably strong linear correlation with mean annual surface water temperatures from the world ocean atlas (compilation by Muller et al. [1998]). The correlation is strong regardless what slice of the upper ocean between 0 and $30 \mathrm{~m}$ depth is chosen for averaging and gradually breaks down as deeper horizons of the water column are taken into consideration (Figure 2). Surface water temperature indeed appears to provide primary control on the value of $\mathrm{U}_{37}^{\mathrm{K}^{\prime}}$ encoded in a marine sediment. The phenomenon appears to be global as reflected by the consistency of many regional calibrations carried out to date using core tops in the Atlantic [Rosell-Mele et al., 1995; Muller et al., 1998], Indian [Sonzogni et al., 1997], and Pacific Oceans [Doose et al., 1997; Herbert et al., 1998; Ohkouchi et al., 1999] and the South China Sea [Pelejero and Grimalt, 1997].

[9] 6. Notably, strongest correlation exists between $\mathrm{U}_{37}^{\mathrm{K}^{\prime}}$ and the mean annual SST at $0 \mathrm{~m}$ depth (Figure 3). Curiously, the equation for the regression line describing this correlation $\left(\mathrm{U}_{37}^{\mathrm{K}^{\prime}}\right.$ $=0.033 T+0.044, r^{2}=0.958, n=370[$ Muller et al., 1998]) is identical within error limits to the widely used laboratory calibration for Ehux [Prahl and Wakeham, 1987; Prahl et al., 1988].

\subsection{Conclusions and Recommendations}

[10] Results from core top analyses indicate that the quantitative $\mathrm{U}_{37}^{\mathrm{K}^{\prime}}-T$ relationship first established for Ehux in laboratory culture provides a realistic estimate of mean annual SST throughout most of the global ocean. There is, without doubt, still much to be learned about the formal biological oceanographic significance of this 

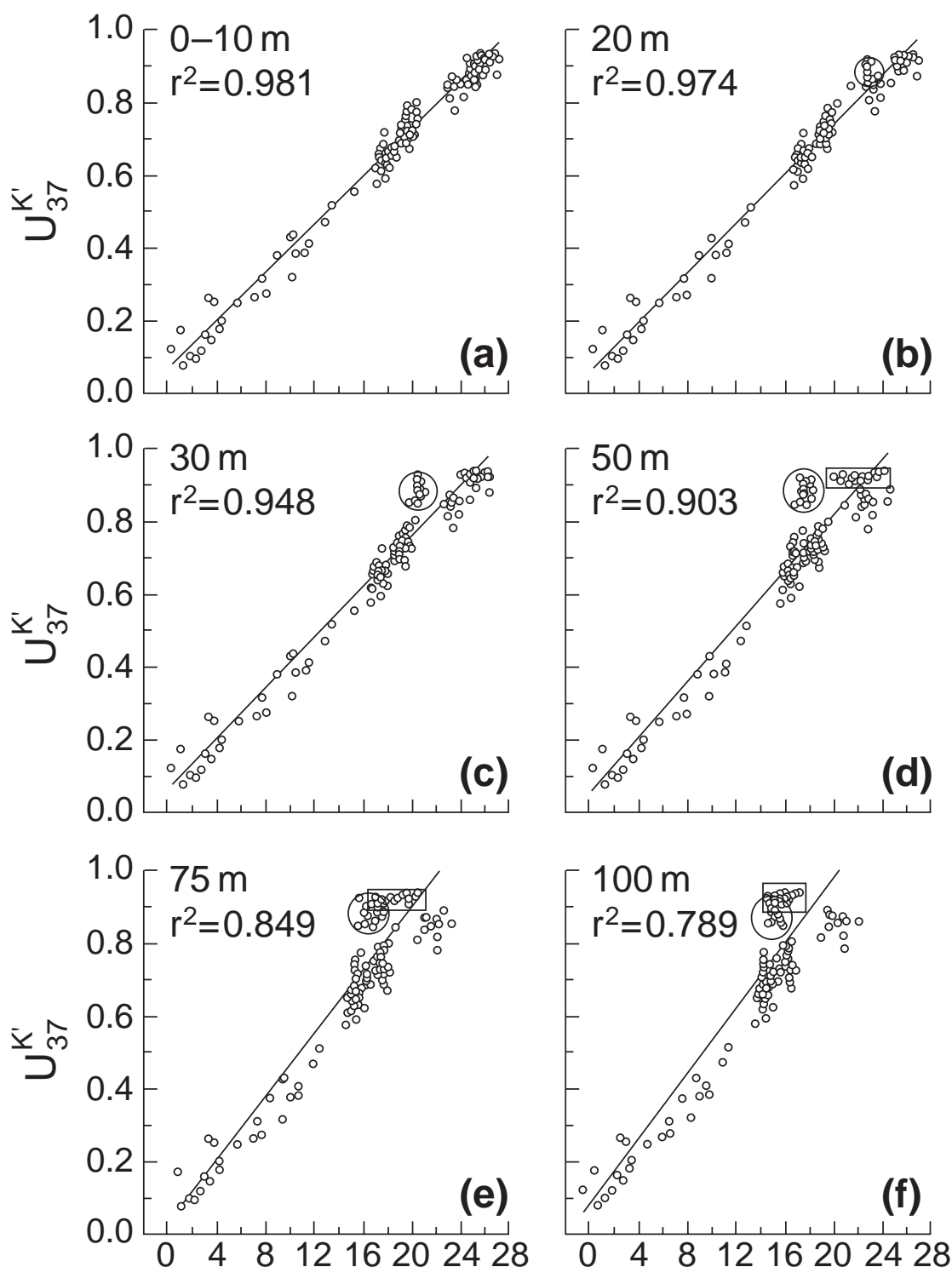

\section{Annual Mean Temperature $\left({ }^{\circ} \mathrm{C}\right)$}

Figure 2. Relationship between $\mathrm{U}_{37}^{\mathrm{K}^{\prime}}$ values measured in a set of surface sediments from the eastern South Atlantic and annual mean temperatures at different depths in respective overlying water columns Reprinted from Muller et al. [1998], with permission from Elsevier Science.

proxy for mean annual SST. However, there is also absolutely nothing that impedes use of the alkenone thermometer as an insightful tool for paleoceanographic study. The community needs to embrace this fact and encourage efforts to strategically use $\mathrm{U}_{37}^{\mathrm{K}^{\prime}}$ measurements for paleoceanographic problem solving.

[11] We recommend that a specific calibration equation be used when absolute water tempera- 


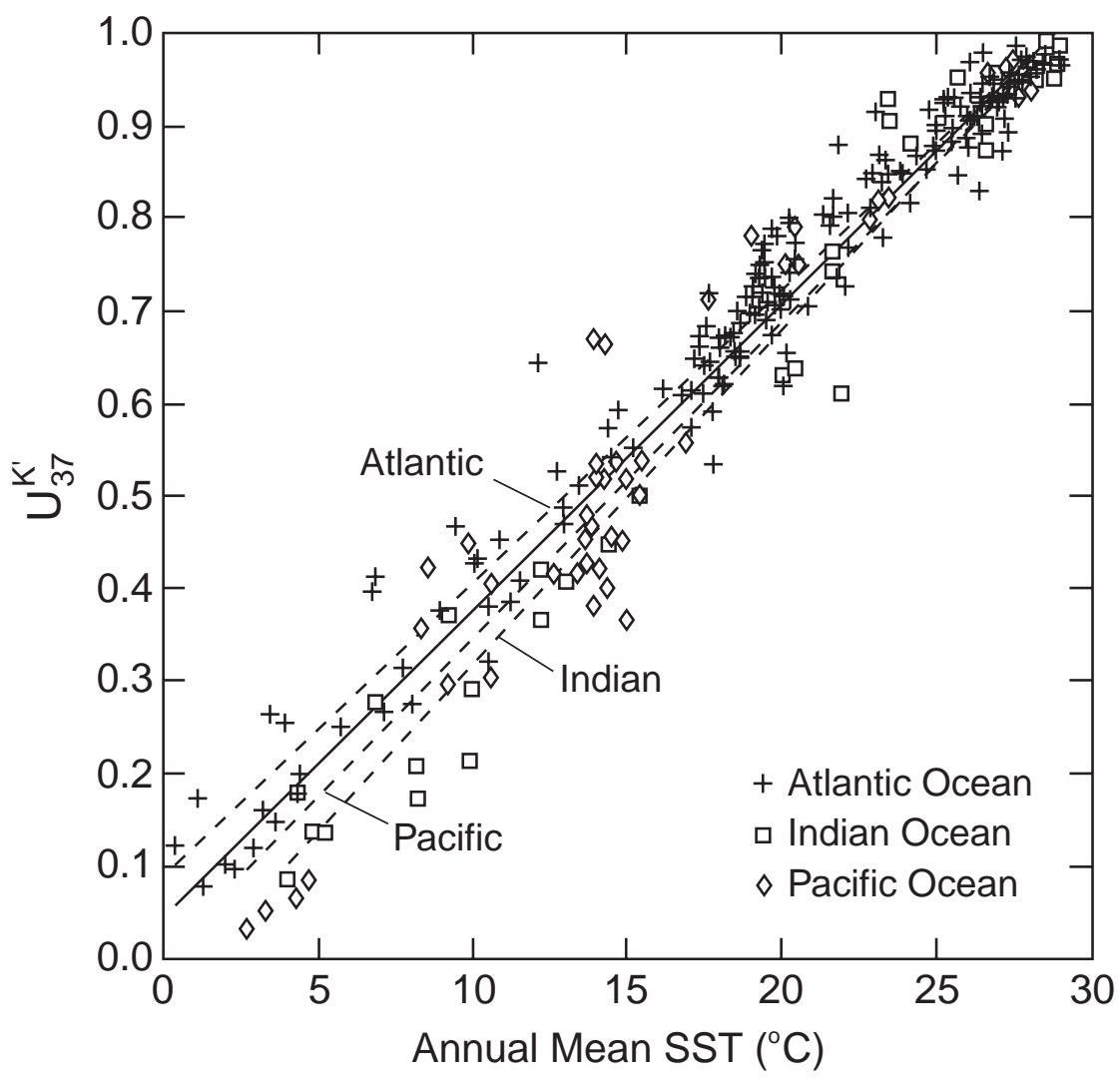

Figure 3. Relationship between $U_{37}^{\mathrm{K}^{\prime}}$ and annual mean sea surface temperature (SST, $0 \mathrm{~m}$ ) for surface sediments from the global ocean between $60^{\circ} \mathrm{N}$ and $60^{\circ} \mathrm{S}$. The global core top calibration (solid line shows $\left.\mathrm{U}_{37}^{\mathrm{K}^{\prime}}=0.033 \mathrm{SST}+0.044\right)$ is identical within error limits to the laboratory calibration established for Ehux by Prahl and Wakeham [1987]. Reprinted from Muller et al. [1998], with permission from Elsevier Science.

ture is calculated and reported in the literature. The calibration of Prahl et al. [1988] $\left(\mathrm{U}_{37}^{\mathrm{K}^{\prime}}=\right.$ $0.034 T+0.039)$, a slight revision of the original equation published by Prahl and Wakeham [1987], is a good benchmark to adopt. It is identical within the error limits of the global core top calibration; the variable $T$ in this equation was based on an actual measured algal growth temperature, and this specific equation has already been widely used in the $\mathrm{U}_{37}^{\mathrm{K}^{\prime}}$ paleothermometry literature. This recommendation should not be strictly enforced, however, as the calibration was only formally constrained over the temperature range of $8^{\circ}-$ $25^{\circ} \mathrm{C}$. Several papers have now shown, for ocean regions with surface waters falling outside this range, that linearity breaks down and applicability of the equation needs further investigation [e.g., Sikes and Volkman, 1993; Rosell-Melé et al., 1995; Sonzogni et al., 1997]. It is also now apparent that a few regions of the ocean exist where absolute temperatures derived from the recommended calibration equation are environmentally unrealistic. Therefore those conducting study in such regions may elect use of an alternative calibration equation based on specific scientific criterion. This option should not be elected simply to achieve a slightly better statistical fit to a limited set of data. Rather, it should be encour- 
aged when it can be founded and supporting evidence is presented. Examples where this option might be employed include regions of the ocean where surface water temperatures are at extremes (polar regions and tropical regions) and values for $\mathrm{U}_{37}^{\mathrm{K}^{\prime}}$ approach the theoretical lower (0) and upper (1) limit of this temperature index. Marginal seas (e.g., Baltic [Schulz et al., 1999]), coastal areas (e.g., fjords [Conte et al., 1994]), and lakes (e.g., Qinghai, Lake Van [Li et al., 1996; Thiel et al., 1997]) represent other possible aquatic settings.

[12] We urge adoption of the policy that sufficient quantitative information be tabulated in all forthcoming publications so that reported temperature estimates based on $\mathrm{U}_{37}^{\mathrm{K}^{\prime}}$ measurements can be completely reassessed if necessary in the future. Furthermore, we recommend that quantitative information on the tetraunsaturated $\mathrm{C}_{37}$ alkenone (K37:4) be reported in all cases where this compound is observed. Although the environmental significance of appearance of K37:4 in sedimentary samples is not yet completely clear, this situation will likely change as active research by the international community continues to refine our specific understanding of alkenone paleothermometry. Careful, comprehensive reporting in the literature of observations about the $\mathrm{C}_{37}$ alkenones will increase the odds of future scientific windfalls in this already proven successful area of organic geochemical research.

\section{Future Research Directions}

[13] Although the equation for a line captures the lion's share of variance between the global core top data set for $\mathrm{U}_{37}^{\mathrm{K}^{\prime}}$ and mean annual SST from the ocean atlas (i.e., $\sim 96 \%$, Figure 3), significant scatter in the relationship nonetheless exists. Results from a recent intercomparison study (A. RosellMelé et al., personal communication, 2000, http://nrg.ncl.ac.uk:8080/climate/ic/intercalibration.htm) indicate this scatter is due to more than mere analytical uncertainty in the measurement of $U_{37}^{K^{\prime}}$. Future alkenone research should be directed to help advance understanding of the environmental cause(s) for this scatter. There is now good reason to believe the scatter reflects fundamental details about alkenone producers and their life history in the surface ocean, and systematic laboratory and field-based studies can illuminate these valuable details. The knowledge to be gained from well-guided future research will advance our quest to reconstruct realistic patterns of change for haptophyte productivity, temperature, and dissolved carbon dioxide in oceans of the past from interrogation of stratigraphic records for alkenone abundance and composition preserved in sediment cores.

\subsection{Core Top Studies}

[14] Given the summary of key findings just presented, it would seem unproductive to encourage further core top analyses for the calibration of $\mathrm{U}_{37}^{\mathrm{K}^{\prime}}$. It is unlikely that this approach would improve the statistics of the global core top calibration now established by Muller et al. [1998] and significantly advance the paleoceanographic utility of $U_{37}^{K^{\prime}}$ measurements. It would seem more valuable at this time to assess the quality of core top measurements included in the data set for the global calibration. For example, answers to the following questions are clearly needed. Are all of the samples in this data set actually modern? Could age uncertainty account for some of the observed scatter in the global core top calibration? Furthermore, are some of the samples included in this core top calibration corrupt due to sediment input via long-distance, lateral transport phenomena [e.g., Benthien and Muller, 2000] and, consequently, not reflective of a record of alkenone production or water temperature in overlying ocean surface waters? 


\subsection{Culture Studies}

[15] Work to date with laboratory cultures has clearly benefited development of the alkenone paleothermometer. This approach has confirmed that $U_{37}^{K^{\prime}}$ values set by alkenone producers are, without doubt, strongly temperature dependent. It has also shown, however, that the temperature response of $\mathrm{U}_{37}^{\mathrm{K}^{\prime}}$ may differ significantly at the interspecies and intraspecies level [Conte et al., 1998a]. Genetic factors probably account for some of these differences but certainly not all. Batch culture work by Epstein et al. [1998] reveals that environmental factors, such as nutrient stress, can potentially influence significantly the $\mathrm{U}_{37}^{\mathrm{K}^{\prime}}$ value recorded by an isothermally grown, single genotype. Chemostat work by Popp et al. [1998] also now suggests that variability in growth rate, an important concern in carbon isotopic fractionation [Laws et al., 1995], probably does not significantly influence unsaturation patterns set by alkenone producers.

[16] The $\mathrm{U}_{37^{\prime}}^{\mathrm{K}^{\prime}} T$ response differences noted within and between alkenone-producing haptophyte species is a definite paleoceanographic concern. Response differences contribute to uncertainty when the $\mathrm{U}_{37}^{\mathrm{K}^{\prime}}$ proxy is employed to reconstruct the paleo-SST record. Uncertainty is greatest when the paleoceanographic goal is set to reconstruct absolute temperatures at given times in the past and least but, nonetheless, still a serious consideration when set to reconstruct relative temperature changes through time.

[17] Work with laboratory cultures should continue to be encouraged as the product of this effort will hone confidence in the reliability of the alkenone paleothermometer. However, future effort should become increasingly experimental and focus on gaining fundamental understanding of the environmental and physiological factors which control the alke- none content and composition of cells. Conducting more culture experiments which deviate from the original calibration line will not in itself add much to the picture we have now assembled after a decade of culture studies. A basic question direly needs to be answered, and laboratory culture experiments provide the best approach to seek the answer. Are the differences in $\mathrm{U}_{37^{-}}^{\mathrm{K}^{\prime}} T$ response now documented between strains of Ehux and its close relative, Gephyrocapsa oceanica (Figure 4), primarily physiological and caused by dissimilar stress response to culturing conditions, or are they truly genetic?

[18] Without doubt, the variation in the $\mathrm{U}_{37}^{\mathrm{K}^{\prime}}-T$ response found in culture studies is clearly a flag for paleoceanographic concern. Better understanding of whether the variance comes from physiological or genetic factors will help determine how paleoceanographers can develop "screening" techniques to ensure that they do not apply inappropriate calibrations or error assessments to geological applications of the $\mathrm{U}_{37}^{\mathrm{K}^{\prime}}$ index. Laboratory work with batch and/or continuous cultures done in conjunction with well-designed field experiments seems essential to gain this fundamental knowledge.

\subsection{Water Column Studies}

[19] Sikes and Volkman [1993] showed that a systematic relationship exists between $\mathrm{U}_{37}^{\mathrm{K}^{\prime}}$ measured in suspended particulate materials (SPM) from surface waters in the Pacific and the temperature from which the SPM was collected. This relationship deviates increasingly from the original $\mathrm{U}_{37^{\prime}}^{\mathrm{K}^{\prime}} T$ calibration for Ehux as temperature decreases (Figure 5). At temperatures below $\sim 5^{\circ} \mathrm{C}$, there is no apparent dependence of $\mathrm{U}_{37}^{\mathrm{K}^{\prime}}$ on temperature. Three alternative causes could account for the deviation of this field calibration from the original Ehux culture calibration: (1) Alkenone produ- 


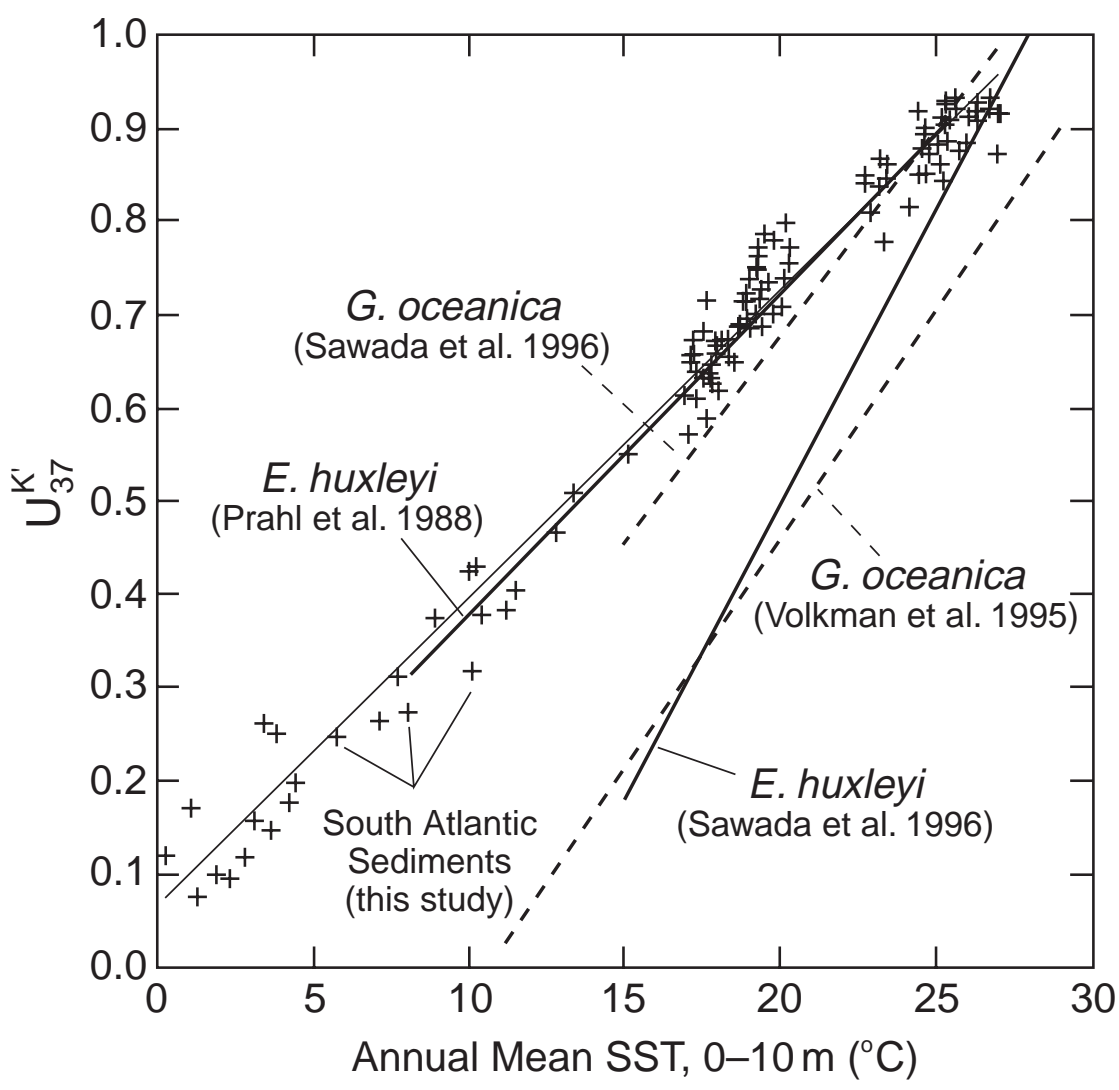

Figure 4. Comparison between $\mathrm{U}_{37}^{\mathrm{K}^{\prime}}-T$ calibration for the eastern South Atlantic using annual mean SST at 0-10 m water depth (crosses and thin solid line) and published culture calibrations for Emiliania huxleyi (thick solid lines) and Gephyrocapsa oceanica (dashed lines). Reprinted from Muller et al. [1998], with permission from Elsevier Science.

cers represented in this set of SPM samples are not genetically the same, and the deviation reflects genetic variation in the $\mathrm{U}_{37}^{\mathrm{K}^{\prime}}-T$ response [e.g., Conte et al., 1998a]; (2) physiological factors besides growth temperature, such as nutrient availability, have influenced, to different degrees, the $\mathrm{U}_{37}^{\mathrm{K}^{\prime}}$ recorded by alkenone producers at the various sampling sites [e.g., Conte et al., 1998a; Epstein et al., 1998]; or (3) actual growth temperature recorded by $U_{37}^{K^{\prime}}$ measured in these SPM samples is not in all cases equivalent to the measured water temperature from which the SPM samples were collected. Given our current limited knowl- edge of alkenone biogeochemistry, none of these alternative explanations can be yet discounted.

[20] Careful study of the upper water column in different oceanographic regions (tropical, subtropical, temperate, subpolar, and polar) is clearly warranted. Concerted effort should be made to put all measurements of alkenone content and composition in as complete of a physical, biological, and chemical oceanographic context as possible. Studies should be designed to evaluate the seasonality of alkenone production in surface waters from 


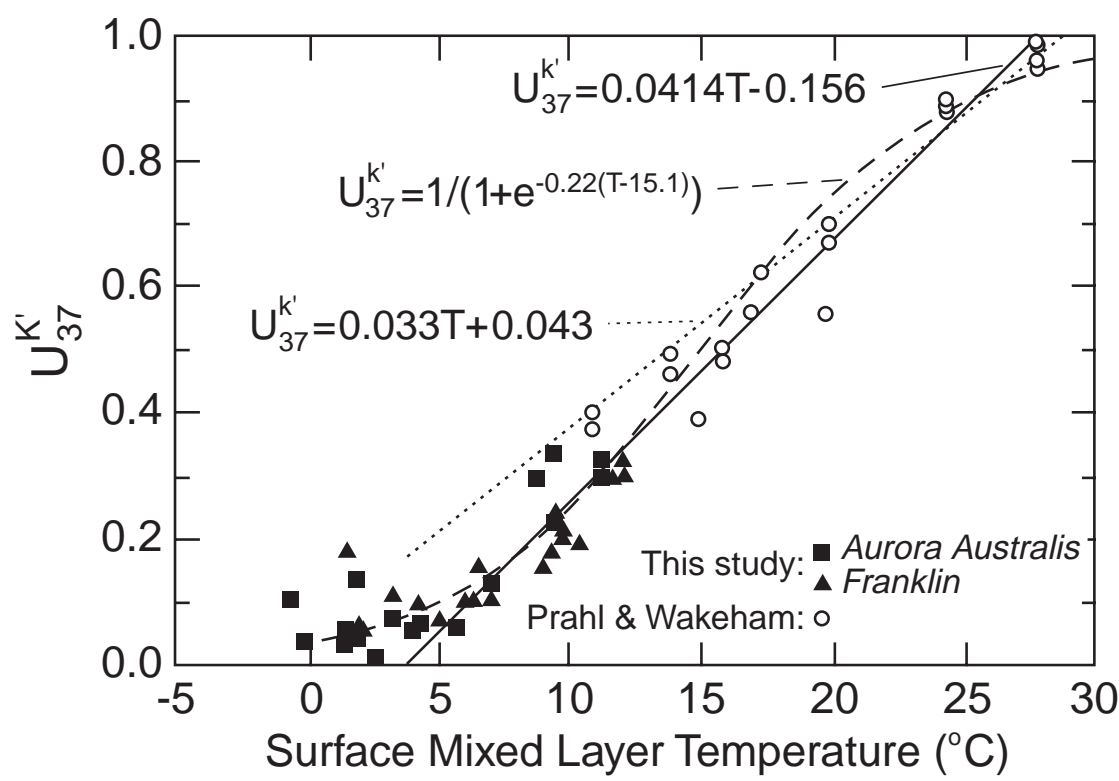

Figure 5. Plot of $\mathrm{U}_{37}^{\mathrm{K}^{\prime}}$ against surface mixed layer temperature for suspended particulate materials collected in surface waters throughout the Pacific (open and solid symbols). Dotted line shows the calibration equation established by Prahl and Wakeham [1987] for Emiliania huxleyi in culture. Reprinted from Sikes and Volkman [1993], with permission from Elsevier Science.

key regions of the ocean and the possibility that alkenone production need not be restricted to the surface mixed layer in each of these regions.

[21] The euphotic zone in many areas of the world ocean is characterized by significant thermal structure. A pronounced subsurface chlorophyll maximum (SCM) is often observed at the base of the euphotic zone within the upper thermocline [Longhurst and Harrison, 1989]. Results from early work with water bottles and sediment traps indicated that alkenone export production in the open NE Pacific originates from SCM prevalent in this region of the world ocean (Figure 6) [Prahl et al., 1993]. Ohkouchi et al. [1999] now provide compelling indirect evidence from sediment analyses that subsurface alkenone production is not an uncommon phenomenon in the Pacific Ocean and follows a predictable regional pattern. The latter conjecture is encouraging and needs to be formally confirmed and qualified. Information to be gained from systematic study of alkenones in surface waters will be invaluable, helping us more accurately interpret the oceanographic significance of unsaturation patterns and carbon isotopic composition encoded by these biomarkers in the marine sedimentary record.

\subsection{Sediment Trap Studies}

[22] Published results for alkenone analyses in year-long sediment trap time series remain few in number. However, information now available in published and unpublished forms reveals that the flux of alkenones to the seabed is not uniform throughout the year anywhere in the ocean. Rather, it is highly seasonal, as first documented in the NE Pacific (Figure 7) and now shown to be true quite widely elsewhere in the ocean (e.g., Arabian Sea [Prahl et al., 


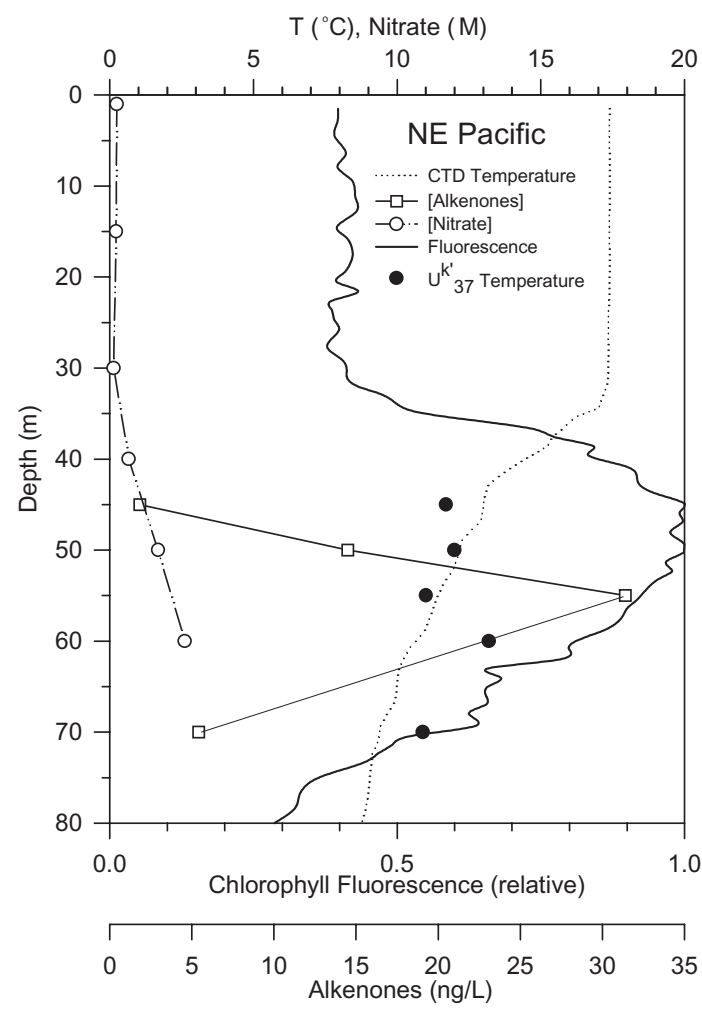

Figure 6. Profile for total $\mathrm{C}_{37-39}$ alkenone concentration and $\mathrm{U}_{37}^{\mathrm{K}^{\prime}}$-derived growth temperature estimates measured with depth in surface waters at a site in the open NE Pacific $\left(41^{\circ} 32.5^{\prime} \mathrm{N}, 131^{\circ} 57.3^{\prime} \mathrm{W}\right)$ in September 1988. Profiles for chlorophyll fluorescence, actual water temperature, and dissolved nitrate/nitrite concentration measured with depth in the same water column are also plotted for reference purposes. Growth temperature estimates were made using the calibration $\left(\mathrm{U}_{37}^{\mathrm{K}^{\prime}}=0.034 T+0.039\right)$ established by Prahl et al. [1988]. Data are from Prahl et al. [2000b].

2000a], Mediterranean Sea [Ternois et al., 1997], NE Norwegian Sea [Thomsen et al., 1998], and Sargasso Sea [Conte et al., 1998b]).

[23] Comparison of alkenone content in average sediment trap particles with that in underlying surface sediment from the NE Pacific [Prahl et al., 1993] also reveals that these biomarkers are not conserved in the sedimentary process; a significant fraction of the rain into the seabed is degraded. The quantitative trend in the NE Pacific suggests that the percentage preserved depends upon redox conditions at the seabed, with suboxic to anoxic sediments showing the highest percentage preservation $(20-30 \%)$ and oxic sediments showing the lowest $(<1 \%)$. Despite major loss of total alkenone signal, $\mathrm{U}_{37}^{\mathrm{K}^{\prime}}$
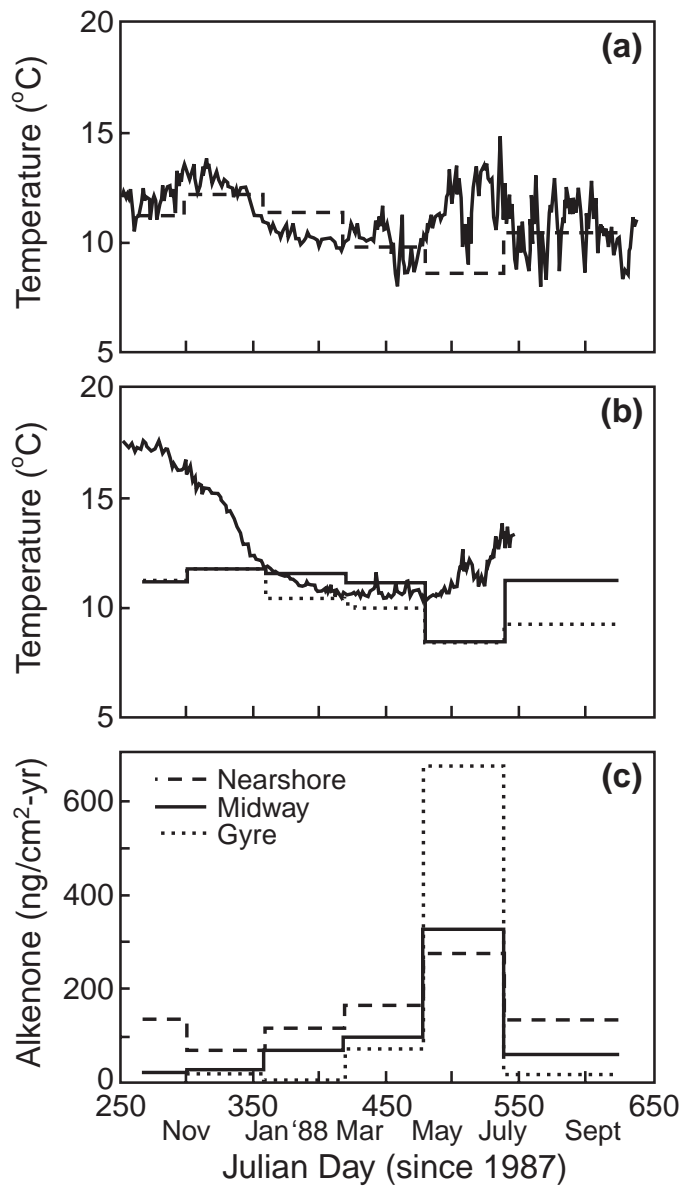

Figure 7. Water temperature estimates from the analysis of $\mathrm{U}_{37}^{\mathrm{K}^{\prime}}$ in samples from sediment trap time series for three sites in the NE Pacific (Nearshore (Fig. 7A) and Midway and Gyre (Fig. 7B)) are compared with the annual records for SST at two National Oceanic and Atmospheric Administration weather buoys located nearby. Fig. 7C displays the record for total alkenone flux in each sediment trap sampling cup. Reprinted from Prahl et al. [1993], with permission from Elsevier Science. 
values in average sediment trap materials weighted for flux display a first-order agreement with those measured in underlying surface sediments. Curiously, however, $\mathrm{U}_{37}^{\mathrm{K}^{\prime}}$ values recorded in the deposited sediments are typically higher than those in the average particle rain from above. Also, the discrepancy appears to increase as sediments become more oxidized, i.e., the total alkenone signal is less efficiently preserved. Is this offset evidence for selective alkenone degradation?

[24] A staunch opponent of sediment traps might emphatically say no! The mismatch is due to the inherent quantitative imperfection of these sampling devices. However, biogeochemists intrigued by the mechanism of organic carbon preservation [Hedges and Keil, 1995] might argue that yes, it is indeed such evidence! However, the process may not be simply selective degradation of the triunsaturated relative to the diunsaturated alkenone. Although that process would account for the direction of offset observed in the sediment trap-sediment comparisons, all attempts to find evidence for significant selective compound degradation, including controlled laboratory experiments with microbes [Teece et al., 1998], have come up empty. So how else could the observations be explained in terms of "selective degradation"?

[25] In the case of the NE Pacific, $\mathrm{U}_{37}^{\mathrm{K}^{\prime}}$ values raining into the seabed are not uniform throughout the year (Figure 7). Furthermore, the greatest deviation is observed during the period of peak flux. If the fraction of total flux surviving burial were disproportionately lower during the time period represented by peak flux, $\mathrm{U}_{37}^{\mathrm{K}^{\prime}}$ values preserved in sediments would appear higher than predicted by the flux weighted annual average for sediment traps. Whether or not this explanation is actually so for the NE Pacific and extrapolates to other regions of the ocean will require further study. Almost certainly, the seasonality of alkenone production varies with oceanic province: sediment traps along the Southern California margin and Gulf of California show far less seasonal variation in coccolithophorid/alkenone flux than the northeast Pacific does [Thunell, 1998a, 1998b]. The prospect is clearly viable and worth investigation. In this regard, it is noteworthy that activity in the deep-sea benthic community can be tightly coupled to biological processes in the surface ocean [Graf, 1989].

[26] We recommend that further work with sediment trap time series be conducted. It is important to establish how the seasonal pattern for alkenone production in surface waters equates with alkenone export to sediments and particularly how this pattern varies from region to region. We know that most of the primary production, including the contribution from alkenone producers, is recycled within the surface ocean. Only a fraction is transmitted to the seabed via sedimentation, and only a fraction of that transmitted is preserved in the sediment record. Given the efficiency with which this filter operates and its potential to shape the meaning of what becomes chemically encoded in the sediment record (our eyepiece to the past), it is of paramount importance to place the sediment record in clear perspective with modern oceanographic processes. A concerted, systematic laboratory and field approach is the only obvious way to identify what we can realistically expect to extract from the sediment record for alkenones about changes in oceanographic conditions and climate in the past.

\section{Acknowledgments}

[27] Support from NSF (OCE-9616851 and OCE9730376) paid for the effort of FGP to write this report and redraft graphical aids borrowed with permission from the literature. 


\section{References}

Benthien, A., and P. J. Muller, Anomalously low alkenone temperatures caused by lateral particle and sediment transport in the Malvinas Current region, western Argentine Basin, Deep Sea Res., 47, Part I, 2369-2393, 2000 .

Brassell, S. C., Application of biomarkers delineating marine paleoclimatic fluctuations during the Pleistocene, in Organic Geochemistry: Principles and Applications, edited by M. H. Engel and S. A. Macko, pp. 699-738, Plenum, New York, 1993.

Brassell, S. C., G. Eglinton, I. Marlowe, U. Pflaumann, and M. Sarnthein, Molecular stratigraphy: A new tool for climatic assessment, Nature, 320, 129133, 1986.

Conte, M. H., G. Eglinton, and L. A. S. Madureira, Longchain alkenones and alkyl alkenoates as palaeotemperature indicators: Their production, flux and early sedimentary diagenesis in the eastern North Atlantic, Org. Geochem., 19, 287-298, 1992.

Conte, M. H., A. Thompson, and G. Eglinton, Primary production of lipid biomarker compounds by Emiliania huxleyi: Results from an experimental mesocosm study in fjords of southwestern Norway, Sarsia, 79, 319-331, 1994.

Conte, M. H., A. Thompson, D. Lesley, and R. P. Harris, Genetic and physiological influences on the alkenone/ alkenoate versus growth temperature relationship in Emiliania huxleyi and Gephyrocapsa oceanica, Geochim. Cosmochim. Acta, 62, 51-68, 1998a.

Conte, M. H., J. C. Weber, and N. Ralph, Episodic particle flux in the deep Sargasso Sea: An organic geochemical assessment, Deep Sea Res, Part I, 45, 1819-1841, 1998b.

Doose, H., F. G. Prahl, and M. Lyle, Biomarker temperature estimates for modern and last glacial surface waters of the California Current system between $33^{\circ}$ and $42^{\circ} \mathrm{N}$, Paleoceanography, 12, 615-622, 1997.

Eglinton, G., S. A. Bradshaw, A. Rosell, M. Sarnthein, U. Pflaumann, and R. Tiedemann, Molecular record of secular sea surface temperature changes on 100-year timescales for glacial terminations I, II and IV, Nature, 356, 423-426, 1992.

Epstein, B. L., S. d'Hondt, J. G. Quinn, and J. Zhang, An effect of dissolved nutrient concentrations on alkenonebased temperature estimates, Paleoceanography, 13, 122-126, 1998.

Freeman, K. H., and S. G. Wakeham, Variations in the distributions and isotopic compositions of alkenones in Black Sea particles and sediments, Org. Geochem., 19, 277-285, 1992.
Graf, G., Benthic-pelagic coupling in a deep-sea benthic community, Nature, 341, 437-439, 1989.

Hedges, J. I., and R. G. Keil, Sedimentary organic preservation: An assessment and speculative synthesis, Mar. Chem., 49, 81-115, 1995.

Herbert, T. D., J. D. Shuffert, D. Thomas, C. Lange, A. Weinheimer, A. Peleo-Alampay, and J.-C. Herguera, Depth and seasonality of alkenone production along the California margin inferred from a core top transect, Paleoceanography, 13, 263-271, 1998.

Kennedy, J. A., and S. C. Brassell, Molecular records of twentieth-century El Nino events in laminated sediments from the Santa Barbara basin, Nature, 357, 62-64, 1992.

Laws, E. A., B. N. Popp, R. R. Bidigare, M. C. Kennicutt, and S. A. Macko, Dependence of phytoplankton carbon isotopic composition on growth rates and $\left[\mathrm{CO}_{2}\right]_{\mathrm{aq}}$ : Theoretical considerations and experimental results, Geochim. Cosmochim. Acta, 59, 1131-1138, 1995.

Li, J., R. P. Philp, F. Pu, and J. Allen, Long-chain alkenones in Qinghai lake sediments, Geochim. Cosmochim. Acta, 60, 235-241, 1996.

Longhurst, A. R., and W. G. Harrison, The biological pump: Profiles of plankton production and consumption in the upper ocean, Progr. Oceanogr., 22, 47-122, 1989.

Madureira, L. A. S., M. H. Conte, and G. Eglinton, Early diagenesis of lipid biomarker compounds in North Atlantic sediments, Paleoceanography, 10, 627-642, 1995.

Muller, P. J., G. Kirst, G. Ruhland, I. von Storch, and A. Rosell-Mele, Calibration of the alkenone paleotemperature index $\mathrm{U}_{37}^{\mathrm{K}^{\prime}}$ based on core-tops from the eastern South Atlantic and the global ocean $\left(60^{\circ} \mathrm{N}-60^{\circ} \mathrm{S}\right)$, Geochim. Cosmochim. Acta, 62, 1757-1772, 1998.

Ohkouchi, N., K. Kawamura, H. Kawahata, and H. Oka$\mathrm{da}$, Depth ranges of alkenone production in the central Pacific Ocean, Global Biogeochem. Cycles, 13, 695704, 1999.

Pelejero, C., and J. O. Grimalt, The correlation between the $U_{37}^{K^{\prime}}$ index and sea surface temperatures in the warm boundary: The South China Sea, Geochim. Cosmochim. Acta, 61, 4789-4797, 1997.

Popp, B. N., F. Kenig, S. G. Wakeham, E. A. Laws, and R. R. Bidigare, Does growth rate affect ketone unsaturation and intracellular carbon isotopic variability in Emiliani huxleyi?, Paleoceanography, 13, 35-41, 1998.

Prahl, F. G., and S. G. Wakeham, Calibration of unsaturation patterns in long-chain ketone composition for paleotemperature assessment, Nature, 330, 367-369, 1987.

Prahl, F. G., L. A. Muehlhausen, and D. L. Zahnle, Further evaluation of long-chain alkenones as indicators 
of paleoceanographic conditions, Geochim. Cosmochim. Acta, 52, 2303-2310, 1988.

Prahl, F. G., G. J. deLange, M. Lyle, M. A. Sparrow, Postdepositional stability of long-chain alkenones under contrasting redox conditions, Nature, 341, 434-437, 1989.

Prahl, F. G., R. B. Collier, J. Dymond, M. Lyle, and M. A. Sparrow, A biomarker perspective on prymnesiophyte productivity in the northeast Pacific Ocean, Deep Sea Res., Part I, 40, 2061-2076, 1993.

Prahl, F. G., J. Dymond, and M. A. Sparrow, Annual biomarker record for export production in the central Arabian Sea, Deep Sea Res., Part II, 47, 1581-1604, 2000a.

Prahl, F. G., M. A. Sparrow, G. Eglinton, Seasonal record for alkenones in sedimentary particles from the Gulf of Maine, Deep Sea Res., Part I, in press, 2000b.

Rosell-Melé, A., G. Eglinton, U. Pflaumann, and M. Sarnthein, Atlantic core-top calibration of the $\mathrm{U}_{37}^{\mathrm{K}^{\prime}}$ index as a sea-surface paleotemperature indicator, Geochim. Cosmochim. Acta, 59, 3099-3107, 1995.

Schulz, H.-M., A. Schöner, and K.-C. Emeis, Long-chain alkenone patterns in the Baltic Sea: An ocean-freshwater transition, Geochim. Cosmochim. Acta, 64, 469-477, 1999.

Sikes, E. L., and J. K. Volkman, Calibration of alkenone unsaturation ratios $\left(\mathrm{U}_{37}^{\mathrm{K}^{\prime}}\right)$ for paleotemperature estimation in cold polar waters, Geochim. Cosmochim. Acta, 57, 1883-1889, 1993.
Sonzogni, C., E. Bard, F. Rostek, D. Dollfus, A. RosellMelé, and G. Eglinton, Temperature and salinity effects on alkenone ratios measured in surface sediments from the Indian Ocean, Quat. Res., 47, 344-355, 1997.

Teece, M. A., J. M. Getliff, J. W. Leftley, R. J. Parkes, and J. R. Maxwell, Microbial degradation of the marine prymnesiophyte Emiliania huxleyi under oxic and anoxic conditions as a model for early diagenesis: Longchain alkadienes, alkenones and alkyl alkenoates, Org. Geochem., 29, 863-880, 1998.

Ternois, Y., M.-A. Sicre, A. Boireau, M. H. Conte, and G. Eglinton, Evaluation of long-chain alkenones as paleotemperature indicators in the Mediterranean Sea, Deep Sea Res., Part I, 44, 271-286, 1997.

Thiel, V., A. Jenisch, G. Landmann, A. Reimer, and W. Michaelis, Unusual distributions of long-chain alkenones and tetrahymanol from the highly alkaline Lake Van, Turkey, Geochim. Cosmochim. Acta, 61, 20532064, 1997.

Thomsen, C., D. E. Schulz-Bull, G. Petrick, and J. C. Duinker, Seasonal variability of the long-chain alkenone flux and the effect on the $\mathrm{U}_{37}^{\mathrm{K}^{\prime}}$-index in the Norwegian Sea, Org. Geochem., 28, 311-323, 1998.

Thunell, R. C., Particle fluxes in a coastal upwelling zone: Sediment trap results from Santa Barbara Basin, California, Deep Sea Res., Part I, 45, 1863-1884, 1998a.

Thunell, R. C., Seasonal and annual variability in particle fluxes in the Gulf of California: A response to climate forcing, Deep Sea Res., Part I, 45, 2059-2083, 1998 b. 